\begin{tabular}{cc}
\hline International Journal of Engineering \& Technology, $7(2.8)(2018) 626-628$ \\
International Journal of Engineering \& Technology \\
SPC \\
Website: www.sciencepubco.com/index.php/IJET \\
Research Paper
\end{tabular}

\title{
A Complex shaped crucible frame structure modelling and finite element analysis for stress and deformation
}

\author{
N.V. Dhandapani ${ }^{1 *}$, R. Manimaran ${ }^{2}$, V. C. Uvaraja ${ }^{3}$, R. Sridhararan ${ }^{4}$ \\ ${ }^{1}$ Professor, Karpagam College of engineering, Coimbatore \\ ${ }^{2}$ Associate Professor, Karpagam College of Engineering, Coimbatore \\ ${ }^{3}$ Associate Professor, Bannari Amman Institute of Technology, Erode \\ ${ }^{4}$ Assistant Professor, SKP Engineering College, Tiruvannamalai \\ *Corresponding Author E-mail: nvdhands@yahoo.com
}

\begin{abstract}
Crucible frame structures are otherwise called as complex frame structures and its study is needed for further improvement in the emerging technology. The frame structure are frequently used an operational system support of other mechanisms of a physical construction and/or steel frame that limits the assembly's extent in this study crucible frame structures are analysed using Finite element analysis and the results are expected in terms of safety for actual use. Based on ANSYS Software, the crucible structure can be meshed (discretized into several parts are called elements). At last, we can apply the boundary conditions and calculate its maximum deformation by applying various loads.
\end{abstract}

Keywords: Frame structure, Finite element analysis, ANSYS

\section{Introduction}

Finite element modelling approach is widely accepted as a method of analysing and validating performance and safety of the structures under given load considerations. Here, the crucible structure is analysed using the above said FEM approach. It is a tool with theoretical validation to evaluate frame structure analysis and get the various principle stress and deformations.

\section{Literature survey}

Sharaban Thohura, Shahidul Islam, explained about the study of the Effect of Finite Element Mesh Quality on Stress Concentration Factor of Plates and structure. Huston, Ronald, Harold Josephs, discussed about the practical Stress Analysis in Engineering Design.

Allan Haliburton Hudson Matlock, used to get the calculative data's and standard values of finite-element analysis of structural frames. Saliman Ali Al-hsinny, Majed Al-Hodaeb, briefly explained about the types of Frames in Reinforced Concrete Structures[1-12]. Controller analysis for non-linear system has been reported [13-23].

\section{Meshing}

The geometry is modelled in Creo CAD software by using important features and is then imported into the analysis software ANSYS for finite element analysis and getting various stresses and deformations. It is meshed by selecting three dimensional terra mesh for getting closeness to the accurate results (i.e., discretising into several smaller entities called elements) for the purpose of analysing by the Finite Element Approach. The figure below shows the meshed model generated using ANSYS. The entire structure is discretised into 31,531 number of tetra-hedral type elements with 1, 38,637 nodes.
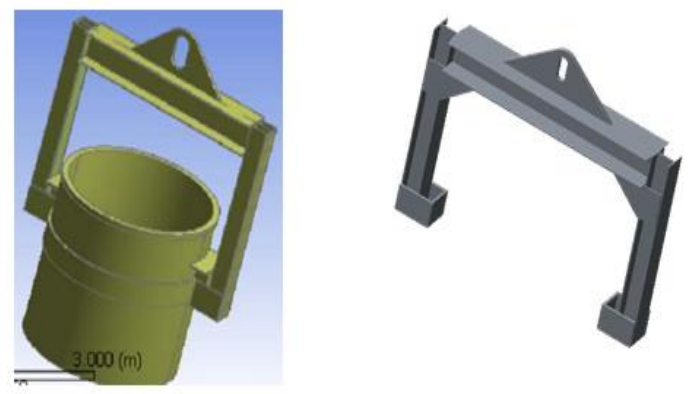

Figure 1 CAD Model of crucible structure

Figure $2 \mathrm{CAD}$ model of structure

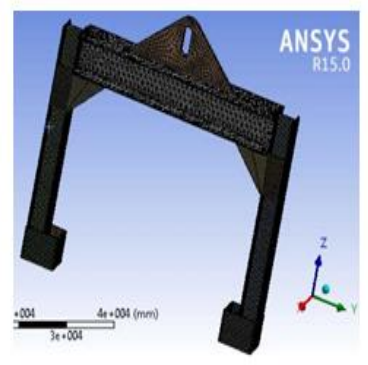

Figure 3 Meshed model for analysis

\section{Boundary Conditions}

After meshing, the meshed model is imported for structural analysis and boundary conditions are applied. The boundary conditions represent the degrees of freedom of each part of the actual model and the loads acting on them. 
A remote force of $80,000 \mathrm{~N}$ is applied at the place where the crucible arm is attached to an external hook. An equal and an opposite force of $80,000 \mathrm{~N}$ is applied as reaction force at the midpoint between the arms, so as to satisfy the equilibrium condition.

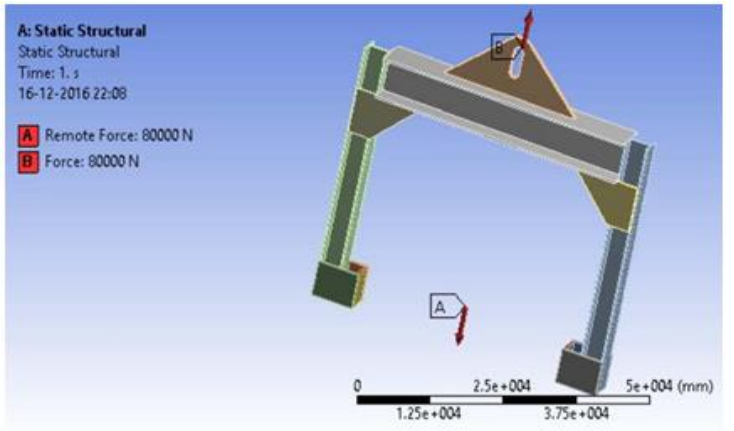

Fig. 4: Boundary Conditions

\section{Results}

\section{Deformation:}

A maximum deformation of $0.013 \mathrm{~mm}$ occurs and the deforming zones are depicted in blue, green and red depending on the increasing magnitude of deformation respectively in the following figure. It is seen that the total and maximum deformation occurs in the Z-direction.

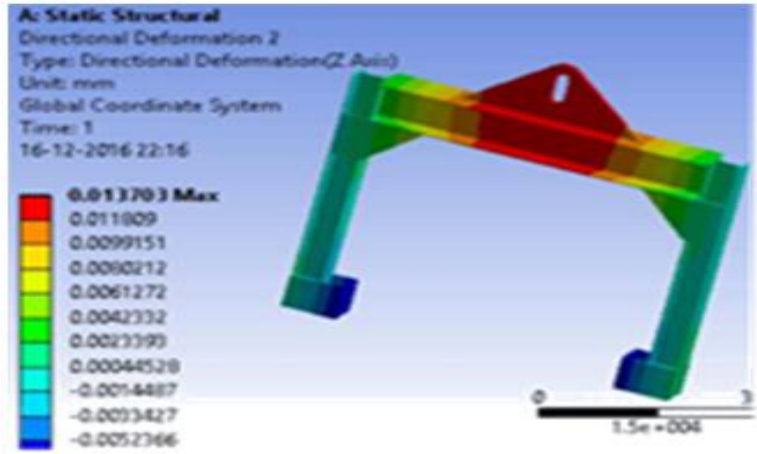

Fig. 5: Directional deformation in $\mathrm{Z}$ axis

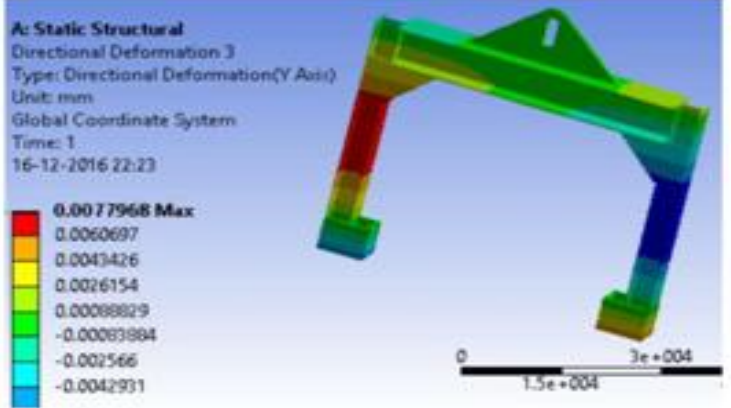

Fig. 6: Total deformation of the structure

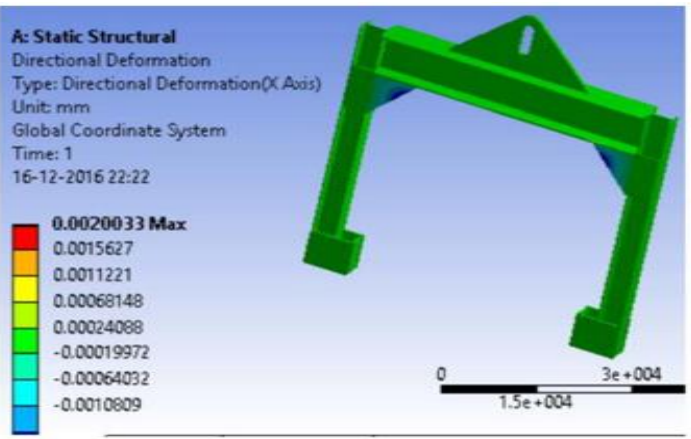

Fig. 7: Directional deformation in $\mathrm{X}$ axis

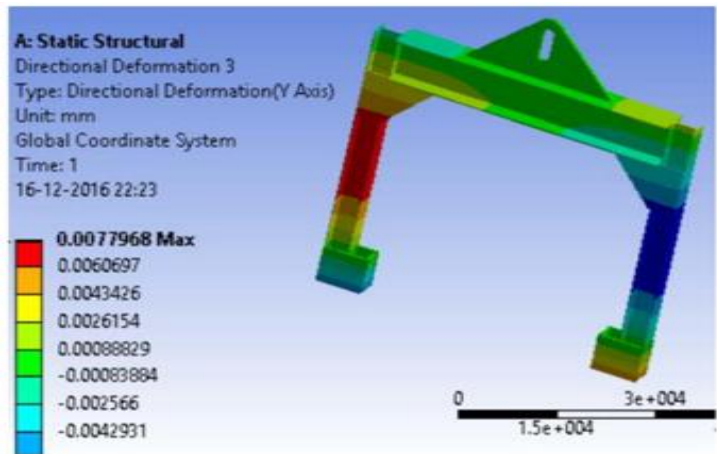

Fig. 8: Directional deformation in $\mathrm{Y}$ axis

\section{Maximum Principal Stress:}

A maximum principal stress of $0.168 \mathrm{MPa}$ is found to be induced in the structure under the given loading conditions. The yield stress value of the medium carbon steel material used here is 310 $\mathrm{MPa}$. Since the working stress (i.e. principal stress in majority of the structure is less in value than the yield strength, it is safe to assume that the structure is safe to handle the design loading conditions.

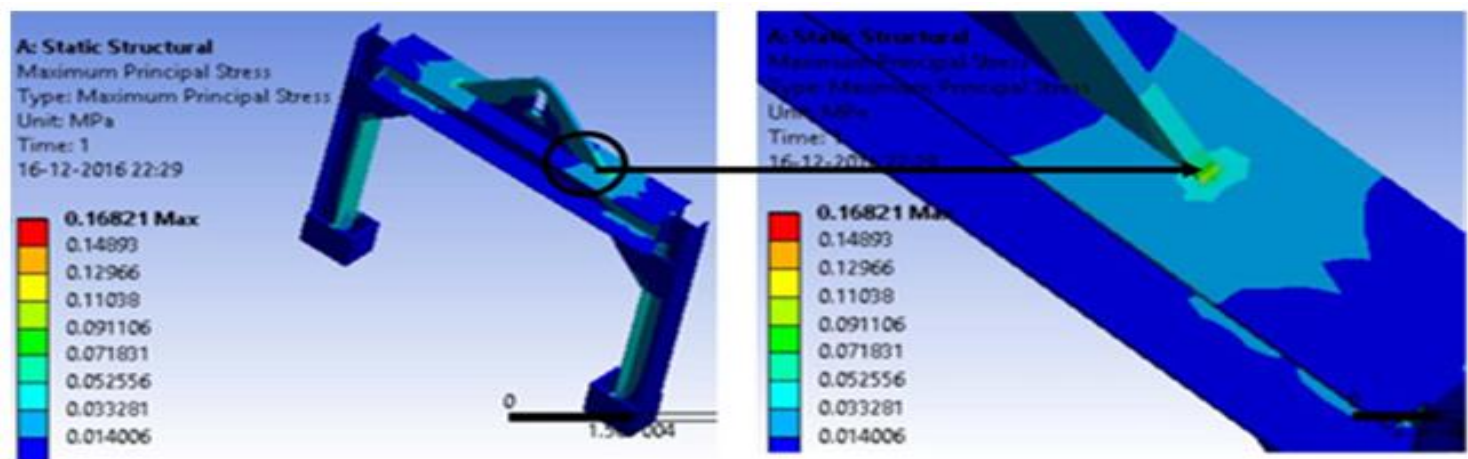

Fig. 9: Maximum Principle Stress

Fig. 10: Details of the Location of Maximum principle stress 


\section{Maximum Equivalent Stress:}

The maximum equivalent or von Mises stress is found to be a maximum of $0.152 \mathrm{MPa}$ in the structure. Yet, it is found that the maximum stress occurs in the slot where the hook is attached to the frame. In other parts of the structure, the stress values in other parts of the major structure is less than this $152 \mathrm{MPa}$ and it is assumed that the structure is safe to withstand the design load conditions.

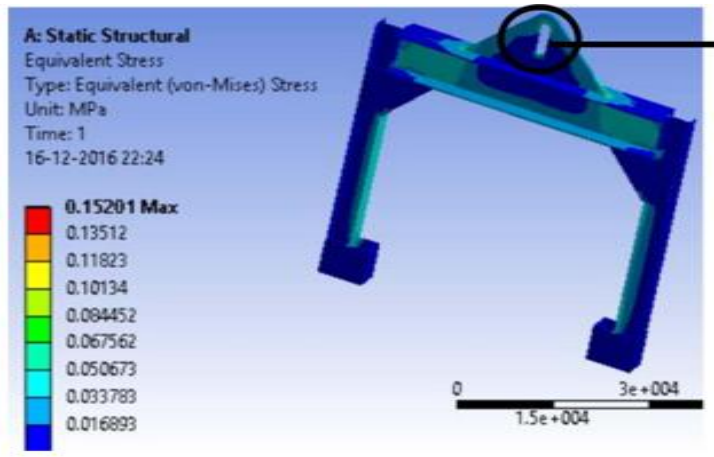

Figure 11: Equivalent Stress Distribution

\section{Conclusion}

The structural deformation and stress distribution is within standard and recommended values for deformation, von Mises stress and maximum principal stress.

Hence, it is concluded that the design of the structure presented for analysis is safe to handle the loads under required performance criteria.

\section{Reference}

[1] Sharaban Thohura,Shahidul Islam, "Study of the Effect of Finite Element Mesh Quality on Stress Concentration Factor of Plates with Holes" Vol 3, Issue 6, December 2013.

[2] Huston,Ronald,Harold Josephs,"Practical Stress Analysis in Engineering Design", 3rd ed. Boca Raton, FL: CRC Press, Taylor \& Francis Group, 2009.

[3] T. Allan Haliburton Hudson Matlock," A finite-element analysis of structural frames",vol 3,pp 54-62,june 2008.

[4] D.Walter,F.Deborah,"Stress Concentration Factors", 3rd ed New York: John Wiley \& Sons, 2008.

[5] V.Marcadon E.Pereira,"Fatigue crack onset detection and observation at high temperature on notched cobalt-base superalloys specimens and fatigue lifetime prediction", vol 3,pp $1-7,2016$

[6] C.Warren,G.Richard,"Roark's Formulas for Stress and Strain",8th ed. New York: McGraw-Hill, 2012.

[7] Dev Dutt Dwivedi1, V. K. Jain2," design and analysis of automobile leaf spring using ansys",vol 2,pp 22-29,November 2012.

[8] S. V. Kumbhar,"Low Cycle Fatigue Analysis of after Treatment Device Induced due to Thermal Load by Using Finite Element Analysis", Applied Mechanics and Materials, Vols. 592-594, pp. 1104-1108, 2014

[9] T. Govardhan,"Load Distribution in a Rolling Element Bearing under Dynamic Radial Load", Applied Mechanics and Materials, Vols. 592-594, pp. 1099-1103, 2014

[10] H.B.Coda,W.S.Venturini,M. H. Aliabadi," A general 3D BEM/FEM coupling applied to elastodynamic continual frame structures interaction analysis".

[11] 1.Saliman Ali Al-hsinny, Majed Al-Hodaeb," Types of Frames in Reinforced Concrete Structures"

[12] D.Arola, P.G.Reinhall,M.G.Jenkins,"An experimental analysis of a hybrid bicycle frame" vol 21-24.

[13] R. Kalaivani, K. Ramash Kumar, S. Jeevananthan, "Implementation of VSBSMC plus PDIC for Fundamental Positive Output Super Lift-Luo Converter," Journal of Electrical Engineering, Vol. 16, Edition: 4, 2016, pp. 243-258.

[14] K. Ramash Kumar,'Implementation of Sliding Mode Controller plus Proportional Integral Controller for Negative Outpu Elementary Boost Converter," Alexandria Engineering Journal (Elsevier), 2016, Vol. 55, No. 2, pp. 1429-1445.

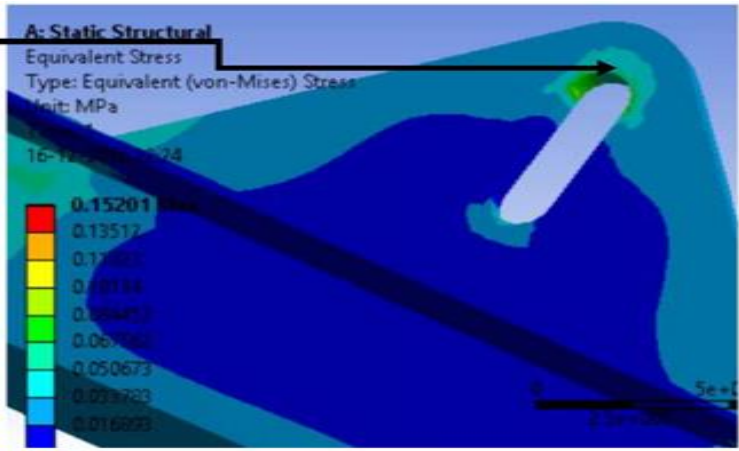

Figure 12: Details of location of the maximum Stress distribution

[15] P. Sivakumar, V. Rajasekaran, K. Ramash Kumar, "Investigation of Intelligent Controllers for Varibale Speeed PFC Buck-Boost Rectifier Fed BLDC Motor Drive," Journal of Electrical Engineering (Romania), Vol.17, No.4, 2017, pp. 459-471.

[16] K. Ramash Kumar, D.Kalyankumar, DR.V.Kirbakaran" An Hybrid Multi level Inverter Based DSTATCOM Control, Majlesi Journal of Electrical Engineering, Vol. 5. No. 2, pp. 1722, June 2011, ISSN: 0000-0388.

[17] K. Ramash Kumar, S. Jeevananthan, "A Sliding Mode Control for Positive Output Elementary Luo Converter," Journal of Electrical Engineering, Volume 10/4, December 2010, pp. 115127.

[18] K. Ramash Kumar, Dr.S. Jeevananthan,” Design of a Hybrid Posicast Control for a DC-DC Boost Converter Operated in Continuous Conduction Mode" (IEEE-conference PROCEEDINGS OF ICETECT 2011), pp-240-248, 978-1-42447925-2/11.

[19] K. Ramash Kumar, Dr. S. Jeevananthan,” Design of Sliding Mode Control for Negative Output Elementary Super Lift Luo Converter Operated in Continuous Conduction Mode", (IEEE conference Proceeding of ICCCCT-2010), pp. 138-148, 978-14244-7768-5/10

[20] K. Ramash Kumar, S. Jeevananthan, S. Ramamurthy” Improved Performance of the Positive Output Elementary Split InductorType Boost Converter using Sliding Mode Controller plus Fuzzy Logic Controller, WSEAS TRANSACTIONS on SYSTEMS and CONTROL, Volume 9, 2014, pp. 215-228.

[21] N. Arunkumar, T.S. Sivakumaran, K. Ramash Kumar, S. Saranya, "Reduced Order Linear Quadratic Regulator plus Proportional Double Integral Based Controller for a Positive Output Elementary Super Lift Luo-Converter," JOURNAL OF THEORETICAL AND APPLIED INFORMATION TECHNOLOGY, July 2014. Vol. 65 No.3, pp. 890-901.

[22] Arunkumar, T.S. Sivakumaran, K. Ramash Kumar, "Improved Performance of Linear Quadratic Regulator plus Fuzzy Logic Controller for Positive Output Super Lift Luo-Converter," Journal of Electrical Engineering, Vol. 16, Edition:3, 2016, pp. 397-408.

[23] Kingston Stanley P, Sanjeevi Gandhi A "INDUSTRIAL EFFLUENT WATER PH NEUTRALIZATION CONTROLLER DESIGN USING LABVIEW AND MATLAB" International Journal of Pure and Applied Mathematics Volume 117 No. 10. (2017), 13-17 doi: 10.12732/ijpam.v117i10.4

[24] T. Padmapriya and V. Saminadan, "Inter-cell Load Balancing technique for multi-class traffic in MIMO-LTE-A Networks", International Journal of Electrical, Electronics and Data Communication (IJEEDC), ISSN: 2320- 2084, vol.3, no.8, pp. 22-26, Aug 2015.

[25] S.V.Manikanthan and V.Rama“'Optimal Performance Of Key Predistribution Protocol In Wireless Sensor Networks" International Innovative Research Journal of Engineering and Technology ,ISSN NO: 2456-1983,Vol-2,Issue -Special -March 2017. 